\author{
Doi 10.5943/ppq/8/2/6 \\ Copyright $($ ) Agriculture College, Guizhou University
}

\title{
Efficacy of Allium sativum extract as post-harvest treatment of fruit rot of mango
}

\author{
Nur Fatimma A, Munirah MS, Sharifah Siti Maryam SAR, Najihah A and \\ Nur Ain Izzati MZ
}

Department of Biology, Faculty of Sceince, Universiti Putra Malaysia, 43400 Serdang, Selangor, Malaysia

Nur Fatimma A, Munirah MS, Sharifah Siti Maryam SAR, Najihah A, Nur Ain Izzati MZ 2018 Efficacy of Allium sativum extract as post-harvest treatment of fruit rots of mango. Plant Pathology \& Quarantine 8(2), 144-152, Doi 10.5943/ppq/8/2/6

\begin{abstract}
Fruit rot caused by Lasiodiplodia species is among the most significant post-harvest fungal disease of mango fruit. The use of chemical synthetic fungicides to control plant diseases can contaminate the environment and affect human health. An alternative method to circumvent these problems is to use extracts from plants that can produce antifungal compounds. Aqueous extract of garlic (Allium sativum) was screened for its inhibitory effect against $L$. theobromae in vitro and it was shown to have antifungal activity by forming an inhibition zone. In addition, L. theobromae growing on garlic extract amended agar did not produce any conidia. Healthy unripe mango fruits were soaked in different concentration of garlic extract for different times. Soaking fruit for 4 hours in $100 \%$ concentration extract prevented lesion development. It is concluded that garlic extract can suppress growth of L. theobromae and improve the marketability of mango fruit without using chemical synthetic fungicides to control post-harvest diseases.
\end{abstract}

Key words - antifungal - mango - Lasiodiplodia theobromae - garlic extract - inhibition

\section{Introduction}

Mango is a tropical fruit widely cultivated and consumed by Asian people. According to Food and Agriculture Organization of the United Nations (FAO) (2010), about 30 million tonnes of mangoes were produced in 2010, second after banana. India is the main producer of mango followed by Philippines, Thailand, Mexico, China, Nigeria, and Brazil (Sekhar et al. 2013). However, post-harvest fungal diseases can reduce production and consumption of mango. Mango is a highly perishable fruit having a very short shelf life with increased respiration rate of ripening process that usually occurs after harvesting (Narayana et al. 1996).

Mango is exposed to many pathogens on every part of a tree and all stages of its life. Fungal pathogens are the most common agents causing the largest number of diseases, including fruit rot. Fruit rot symptoms include black spots with brown colour at the edges, extending rapidly, and finally turns the whole fruit completely black within 2 to 3 days. Lasiodiplodia theobromae (syn. Botryodiplodia theobromae), family Botryosphaeriaceae, is the causal agent of stem end rot of mango fruit. This fungus also causes dieback symptoms in orchards (Johnson et al. 1991). 
Farmers generally use synthetic chemical fungicides to control post-harvest diseases by spraying or soaking fruits and vegetables (Park et al. 2005). The use of chemical fungicides such as benomyl, thiabendazole, prochloraz and carbendazim for controlling post-harvest diseases in mango is usually very effective (Yenjit et al. 2004, Akem 2006). However, excessive use of chemical fungicides has led to chemical residue in fruits, environment pollution and harmful effects on human health (Okigbo \& Osuinde 2003). This has led to increase demand from consumers for fruits and vegetables that are free from chemical fungicides.

In this study, Allium sativum L. was chosen for its potential use as an antifungal agent for post-harvest treatment of mango fruit. Allium sativum (garlic) contains natural fungicide substances active against many fungal species (Slusarenko et al. 2008). In fresh garlic extract the most important biologically active substance is called allicin (Josling 2001, Vasile et al. 2012). There are many reports outlining the antimicrobial properties of allicin including its activity against Gramnegative and Gram-positive bacteria, its antifungal activity against Candida albicans, and antiprotozoal activity against Entamoeba histolytica and Giardia lamblia (Josling 2001, Curtis et al. 2004, Slusarenko et al. 2008, Vasile et al. 2012). In this study, water was used as the solvent to extract active components. The purpose of using water was to produce a homemade extraction, without using any alcohol solvents. According to Patel \& Patel (2016), water is used in pharmacologically test by either decoction (hot) or extraction (hot or cold) in the same manner, as the traditional medicine is prepared. The extraction solvents or chemicals should not have toxic effects or strong interfering effects on living cells. On the other hand, water extraction product mainly contains metals, ions, high hydrophilic compounds and water-soluble protein or enzymes. Therefore, the extracts obtained from water-based extracts are safe to humans and animals. The objectives of the study were to determine the efficacy of Allium sativum extract against Lasiodiplodia theobromae under in vitro and in vivo conditions for post-harvest treatment of mango.

\section{Materials \& Methods}

\section{Fungal cultures and Allium sativum cloves extract}

Three isolates of Lasiodiplodia theobromae (A1718, A1719 and M1560) were obtained from Mycology Laboratory, Department of Biology, Faculty of Science, Universiti Putra Malaysia. The isolates were previously isolated from mango in Telok Mas, Melaka and Bota Kiri, Perak. The isolates were identified based on beta tubulin and internal transcribed spacer (ITS) sequences analysis by Munirah (2017). Lasiodiplodia theobromae isolates were confirmed pathogenic and caused fruit rot disease on mango (Munirah 2017).

Fresh garlic cloves (A. sativum var. sativum) (artichoke garlic from China, imported and packed by Eng Sheng Sdn. Bhd.) were purchased from a retail store at in Selangor. The cloves were peeled and surface sterilised using tap water and sterile distilled water for 15 minutes and allowed to air dry at $27 \pm 2^{\circ} \mathrm{C}$. Approximately, $700 \mathrm{~g}$ of garlic cloves were blended in $700 \mathrm{ml}$ sterile distilled water. They were homogenised using a blender (Waring Commercial Blender, Waring Products) under high mode for 2 minutes. The extract was then filtered through four folds of sterile cheesecloth followed by Whatman filter paper (No. 1) and sterile syringe filter with a pore size of $0.22 \mu \mathrm{m}$ to obtain garlic extract. This extract was considered to be $100 \%$ concentration and stored at $4^{\circ} \mathrm{C}$ until subsequent use.

\section{Turbidity level of Allium sativum cloves extract}

The turbidity level of the extract was determined using a slight modification to the method of Alli et al. (2011) in which different concentrations of extract $(25 \%, 50 \%$ and $75 \%)$ were prepared using sterile distilled water. Each dilution of the extract was placed in a $1.5 \mathrm{ml}$ spectrophotometer semi-micro cuvette with two clear sides and the turbidity determined using a spectrophotometer (Genesys 20, Thermo Spectronic) at a wavelength of $670 \mathrm{~nm}$. This wavelength is the optimum wavelength of this sample for light to penetrate the solution and to read the absorbance. 


\section{In vitro antifungal effects of extracts on Lasidiplodia growth}

In vitro antifungal effects of the extracts on fungal growth were identified according to the method described by Mondali et al. (2009), Nene \& Thapilyal (1993) with slight modification. The garlic extract and potato dextrose agar (PDA) were mixed in sterilised petri plates and each plate was inoculated with a mycelia disc $(9 \mathrm{~mm}$ diameter) taken from 7-days-old PDA culture. All plates were incubated at room temperature of $25^{\circ} \mathrm{C} \pm 2{ }^{\circ} \mathrm{C}$ for 7 days. The diameter of inhibition zone was measured for seven successive days. Percentage inhibition was calculated using the formula (Mondali et al. 2009):

$$
\% \mathrm{FG}=\mathrm{DC}-\mathrm{DR} / \mathrm{DC} \times 100
$$

Where:

$$
\begin{aligned}
& \% \mathrm{FG}=\text { percentage of inhibition of fungi growth } \\
& \mathrm{DC}=\text { diameter of control } \\
& \mathrm{DR}=\text { diameter of test }
\end{aligned}
$$

\section{Fungal development, sporulation and germination test}

A conidial suspension was then prepared from the 7-days-old cultures. The conidia were counted using a haemocytometer and a light microscope (OLYMPUS CX31). Conidia were also incubated in distilled water for 24 hours to record germination. Germination was recorded once the germ tube could be clearly observed.

The experimental data were analysed using IBM SPSS Statistics 21 for Windows System. The data was analysed using one-way analysis of variance (ANOVA). Tukey's HSD test was used to find the significant difference among means at the probability level of $p<0.05$. Two-way ANOVA was applied to determine the significant difference of total number of conidia and germ tubes between the controls and treatments for each different isolate.

\section{In vivo antifungal effects of garlic extract on Lasidiplodia growth}

Fresh and healthy mangoes, visibly free from any physical damage and disease, were used in this study. The mangoes of Chok Anan origin from Melaka were obtained from Pasar Borong Selangor, Seri Kembangan, Selangor. They were washed under running tap water and surface sterilised with $1 \%$ sodium hypochlorite solution for 2 minutes, rinsed twice with sterilised distilled water and then dried using sterile filter paper. Garlic extract was prepared at a series of $25 \%, 50 \%$, $75 \%$ and $100 \%$ concentrations. The mangoes were soaked in different concentrations for 1,2 or 4 hours. Three replicates mangoes for each concentration of garlic extract were used. Fruit soaked in sterile distilled water served as control. A $9 \mathrm{~mm}$ disc taken from the edge of $L$. theobromae (isolate A1718) colony was placed onto the fruit. The mangoes were kept in sterile containers for 7 days at $27 \pm 2{ }^{\circ} \mathrm{C}$. The experiment was repeated twice.

The day that a lesion was first observed was noted, and the size of any lesion was measured after 7 days. Lesion length (along the long axis of the fruit) and width (along the short axis of the fruit) were measured. It was assumed that lesions grew in a circular manner so the diameter (LD) was evaluated as proposed by Kouame et al. (2010), LD $(\mathrm{mm})=$ [Lesion length + lesion width $] / 2$. Data were analysed using two-way ANOVA and Tukey's HSD test was used to find the significant difference among means at the probability level of $\mathrm{p}<0.05$.

\section{Results}

\section{In vitro screening of garlic extracts}

Aqueous extraction of the garlic extract $(100 \%)$ significantly inhibited mycelial growth of all L. theobromae isolates at $\mathrm{p}<0.05$. The highest mycelial inhibition was recorded for isolate M1560 with garlic aqueous dilutions rendering a $61.04 \%$ inhibition of fungal pathogen followed by $L$. theobromae isolate A1718, which was $35.47 \%$ and L. theobromae isolate A1719 with 32.90\% (Fig. 1). Control plate of isolates A1718, A1719 and M1560 formed dark grey colonies with cottony mycelia and produced black pigmentation from reverse plate. However, the culture plates treated 
with aqueous garlic extract produced white-pale grey fluffy feature and produced white-grey pigmentation.

The garlic extracts significantly affected conidial production with no conidia being produced on any of the plates that contained extract. In the control plates, isolate A1719 produced $2.8 \times 10^{4}$ conidia/ml, A1718 produced $1.6 \times 10^{4}$ conidia/ml and isolate M1560 produced $1.2 \times 10^{4}$ conidia/ml. Turbidity level $\left(\mathrm{OD}_{670}\right)$ of the extracts, determined using a spectrophotometer with a wavelength of $670 \mathrm{~nm}$, was 1.507 (100\% extract), 1.285 (75\% extract), 0.429 (50\% extract) and (0.099 (25\% extract).
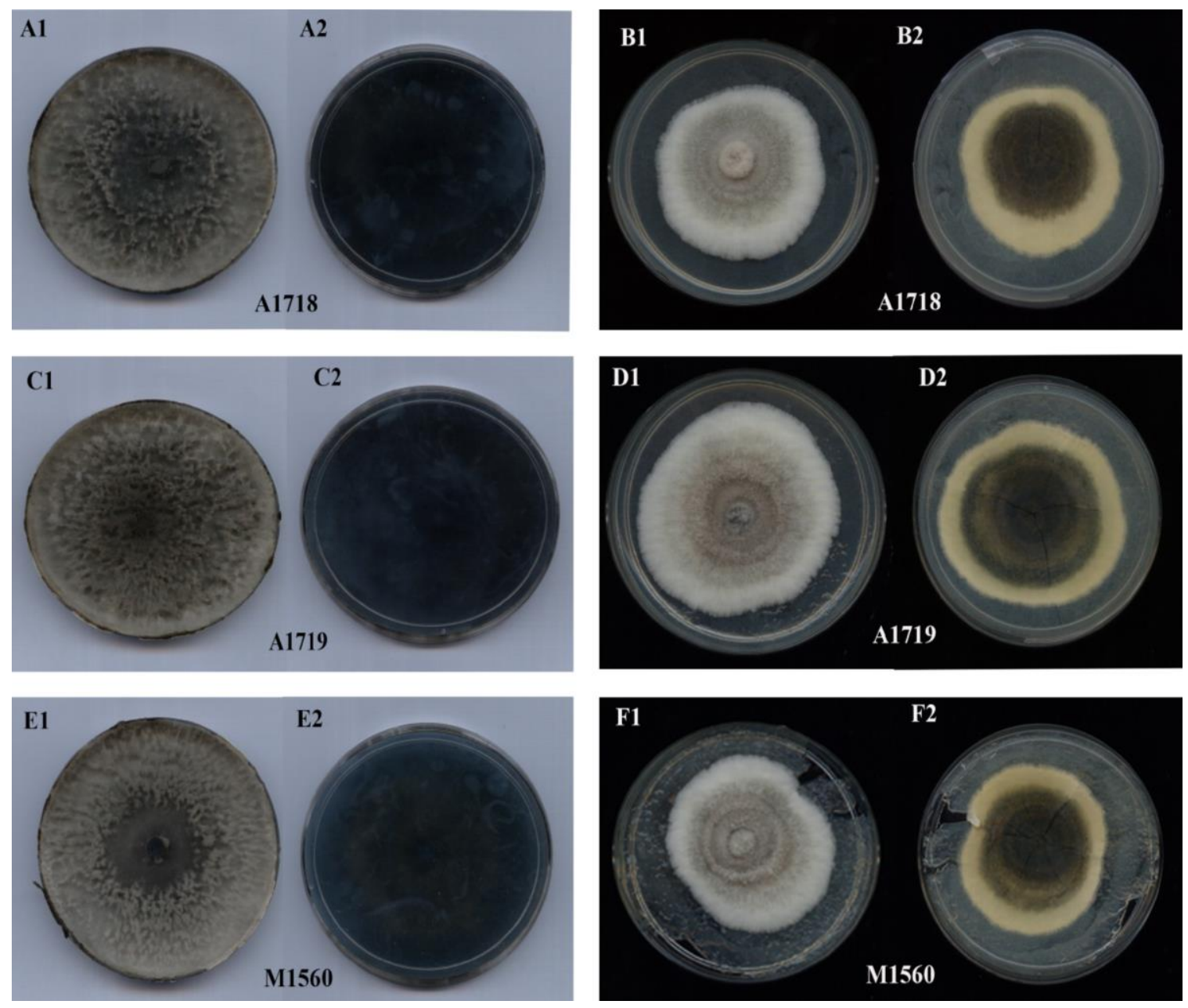

Fig. 1 - In vitro inhibition effect of garlic extract on the growth of three $L$. theobromae isolates (A1718, A1719, M1560). A, C, E Control plates of isolates A1718, A1719 and M1560. B, D, F Plates of isolate A1718, A1719 and M1560 treated with aqueous garlic extract.

\section{In vivo antifungal effects of garlic extracts on Lasidiplodia theobromae isolate A1718}

Garlic extract had a significant effect on the growth of $L$. theobromae. Post-harvest soaking of mango fruit in different concentrations of extract and for different times suppressed lesion development on the fruit. Based on lesion size produced by the pathogen on inoculated mango, there were significant differences between the control and treated mangoes. Among the treated mangoes, there were also significant differences among the concentrations of garlic extract $(\mathrm{p}<0.05)$.

Fruit treated with a concentration of $100 \%$ garlic extract had small lesions compared to other concentrations (Figs 2-4, Table 1). Soaking in 100\% concentration of extract for 4 hours gave the best control of lesion development while soaking in $25 \%$ extract for 1 hour gave no control and resulted in a lesion of $33.8 \mathrm{~mm}$ diameter, which was the same size as that produced following soaking fruit in water for one hour. 
All treatments significantly reduced the lesion diameter on treated mangoes compared to the control. Although there were no significant differences found to other treatments of garlic with different concentrations of extract and period of soaking of mangoes in extract, the treatments worked best to inhibit $L$. theobromae growth on the mangoes. The interaction between the effects of concentration of garlic extract and the effects of period of soaking mangoes in extract was also reported. The F-ratio was not significant at $p>0.05$ as it was assumed that there were no significant interaction effects between the concentration of garlic extract and period of soaking mangoes on lesion diameter.

\section{Discussion}

The radial growth of $L$. theobromae was inhibited under in vitro condition by aqueous extracts of A. sativum, showing the presence of antifungal substances in the plant tissue. Other researchers have reported similar results with different pathogens using A. sativum extract (Alli et al. 2011, Perelló et al. 2013, Shinde et al. 2016). According to Harris et al. (2001), allicin, diallyl trisulphide and ajoene are the active compounds in garlic that give inhibitory activity against pathogens such as bacteria, fungi and several insects. Sterile distilled water was used as a solvent for active component extraction since another aim for this study was to demonstrate that homemade plant extract without using any solvent or chemicals could control pathogens. According to Arora \& Kaur (2007) there are many methods that can be used to prepare plant extracts and the methods used will affect the types of specific activity including antifungal and antioxidant. Different methods of extraction and dilution solvents influence the extraction of different chemical compounds and physiological properties within plants. For that reason, the different extracts may contain different chemical constituents or compounds, or the same compounds in varying quantities (Mendonca-Filho 2006, Senhaji et al. 2013). Many studies support that aqueous garlic extract preparations give the best result in antimicrobial activity including antifungal activity. Senhaji et al. (2013) showed that complete (100\%) mycelia inhibition of Botrytis cinerea could be achieved using $60 \%$ aqueous dilution of crude garlic.

Garlic extract also affected morphological characteristics of $L$. theobromae. PDA amended with garlic extract produced different mycelium colours. The garlic extract also inhibited the production of conidia. In control culture colonies of $L$. theobromae, the entire surface of plates after 7 days incubation was covered with grey cottony aerial mycelium, and when the underside was viewed, there was black pigmentation. According to Ni et al. (2012), L. theobromae on PDA initially produced white, fluffy aerial mycelia that rapidly covered the medium within 2 days incubation, which became pale olivaceous grey within 3-4 days; pycnidia formed after 710 days. The pycnidia are the cause of the black pigmentation. Hence, there were differences between treatment and control based on macroscopic morphological features. Perelló et al. (2013) studied the effects of garlic juice on conidial germination of Drechslera tritici-repetis, Bipolaris sorokiniana and Septoria tritici. At higher concentrations of garlic juice, they found that fewer conidia germinated and the hyphae were abnormal. Another study by Daniel et al. (2015) showed that germination of Botrytis cinerea and Penicillium expansum conidia was completely inhibited at concentrations of 20-80\% aqueous extract of garlic, whereas for ethanol extracts, conidial germination was completely inhibited at all concentrations except at the lowest concentration of $2.5 \%$. This is because of volatile substances released from ethanol-extracted garlic.

Mangoes that were soaked in sterile distilled water for 4 hours produced larger lesions than those soaked for 2 and 1 hour(s). This might be due to the longer soaking causing an increase in the humidity of the fruit and hence triggering the germination of latent fungi.

Synthetic chemical fungicides have been used in a wide range of crops including mango for both pre- and post-harvest control of diseases (Arauz 2000). However, synthetic fungicides can affect animal and human health and contaminate the environment due to residual toxicity. Hence, alternative methods that can replace chemical fungicides, such as using natural products from plants should be fully investigated. 
Table 1 Lesion diameter on mango fruit 7 days post inoculation.

\begin{tabular}{ccc}
\hline Treatment & Period of soaking fruit (hours) & Means of lesion diameter $(\mathbf{m m})$ \\
\hline $100 \%$ & 1 & $15.20^{\mathrm{ab}}$ \\
Garlic extract & 2 & $9.50^{\mathrm{ab}}$ \\
& 4 & $1.80^{\mathrm{a}}$ \\
\hline $75 \%$ & 1 & $28.80^{\mathrm{bc}}$ \\
Garlic extract & 2 & $18.80^{\mathrm{bc}}$ \\
& 4 & $4.90^{\mathrm{ab}}$ \\
\hline $50 \%$ & 1 & $31.00^{\mathrm{bc}}$ \\
Garlic extract & 2 & $24.00^{\mathrm{bc}}$ \\
& 4 & $15.00^{\mathrm{ab}}$ \\
\hline $25 \%$ & 1 & $33.80^{\mathrm{bc}}$ \\
Garlic extract & 2 & $30.00^{\mathrm{bc}}$ \\
& 4 & $18.30^{\mathrm{bc}}$ \\
\hline Inoculated control & 1 & $33.80^{\mathrm{c}}$ \\
(sterile distilled water) & 2 & $35.50^{\mathrm{c}}$ \\
\hline Non-inoculated control & 4 & $37.80^{\mathrm{c}}$ \\
(sterile distilled water) & 1 & $0^{\mathrm{a}}$ \\
& 2 & $0^{\mathrm{a}}$ \\
& 4 & $0^{\mathrm{a}}$ \\
\hline
\end{tabular}

*Values are means of three replicates of two repetitions of lesion diameter. Mean values followed with different letters are significantly different $(\mathrm{p}<0.05)$ according to variable of different concentration of garlic extract. The mean difference is significant at the 0.05 level
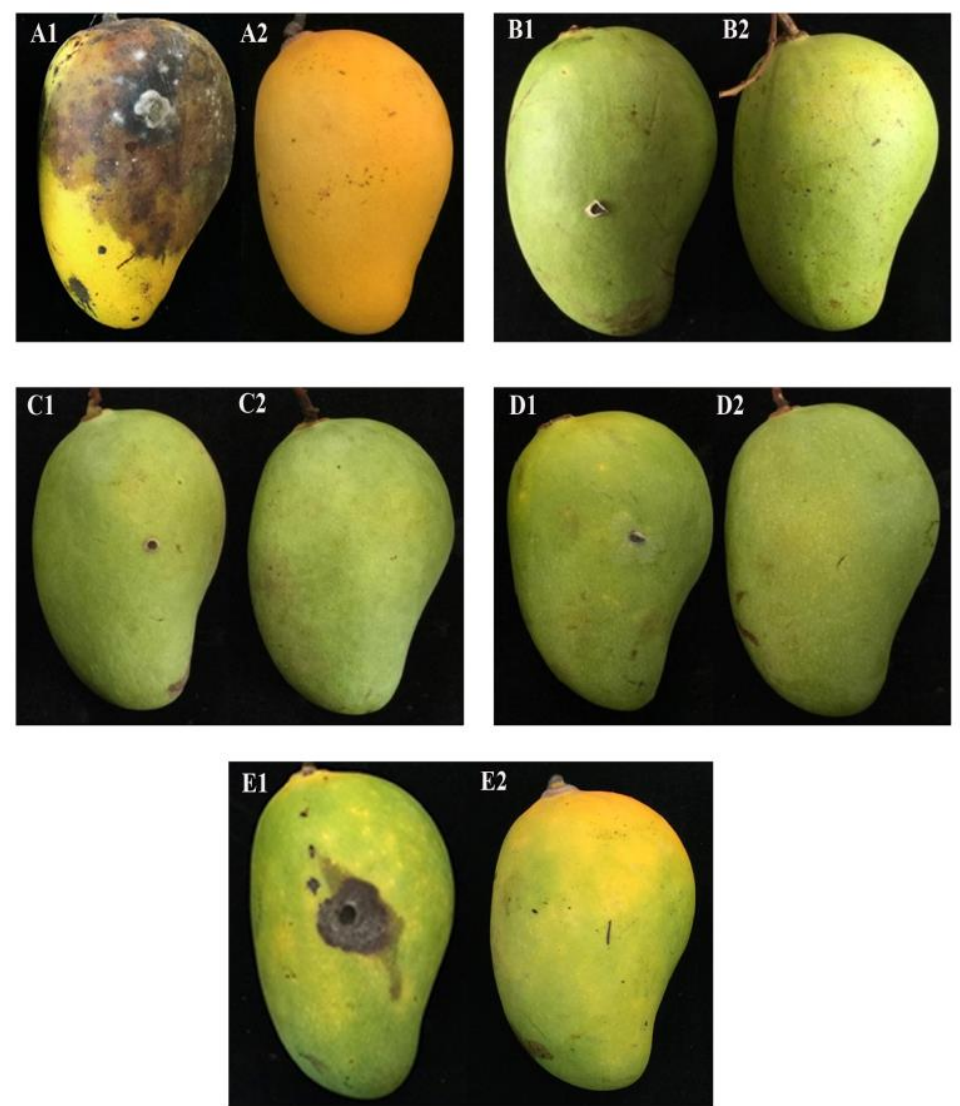

Fig. 2 - Mango fruit 7 days after being soaked in garlic cloves extract for 4 hours. A Inoculated A1 and non-inoculated A2 control mango soaked in sterile distilled. B Inoculated B1 and noninoculated B2 mango soaked in $100 \%$ extract. C Inoculated C1 and non-inoculated C2 mango soaked in $75 \%$ extract. D Inoculated D1 and non-inoculated D2 mango soaked in 50\% extract. E Inoculated E1 and non-inoculated E2 mango soaked in 25\% extract. 

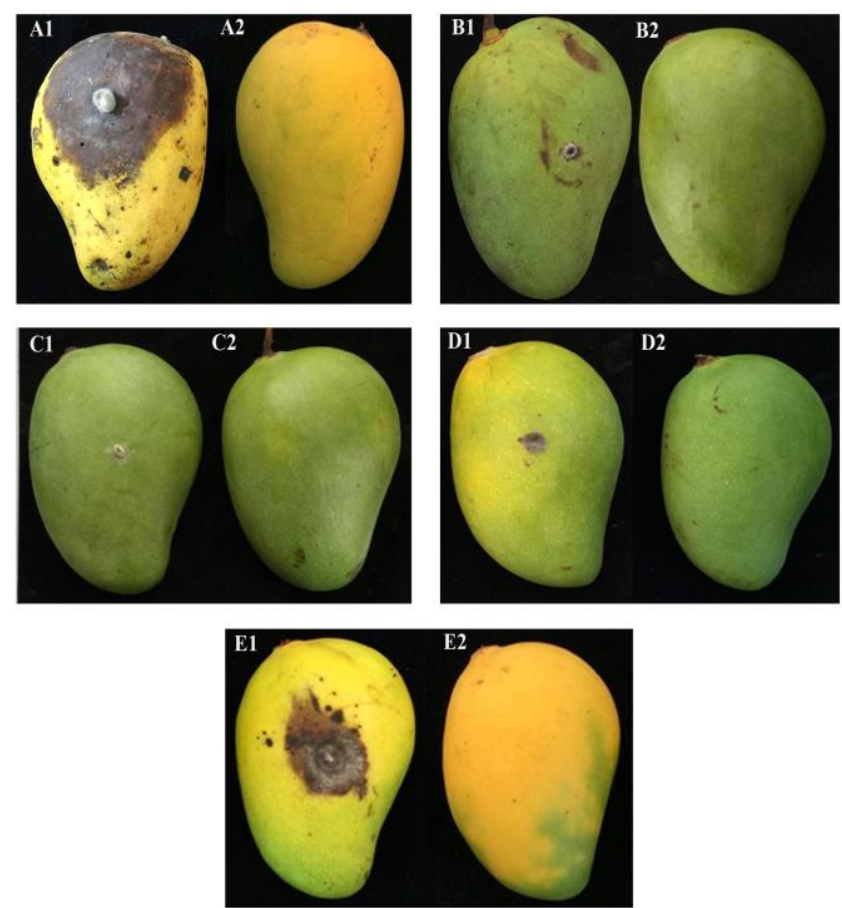

Fig. 3 - Mango fruit 7 days after being soaked in garlic cloves extract for 2 hours. A Inoculated A1 and non-inoculated A2 control mango soaked in sterile distilled. B Inoculated B1 and noninoculated B2 mango soaked in $100 \%$ extract. C Inoculated C1 and non-inoculated C2 mango soaked in $75 \%$ extract. D Inoculated D1 and non-inoculated D2 mango soaked in 50\% extract. E Inoculated E1 and non-inoculated E2 mango soaked in $25 \%$ extract.
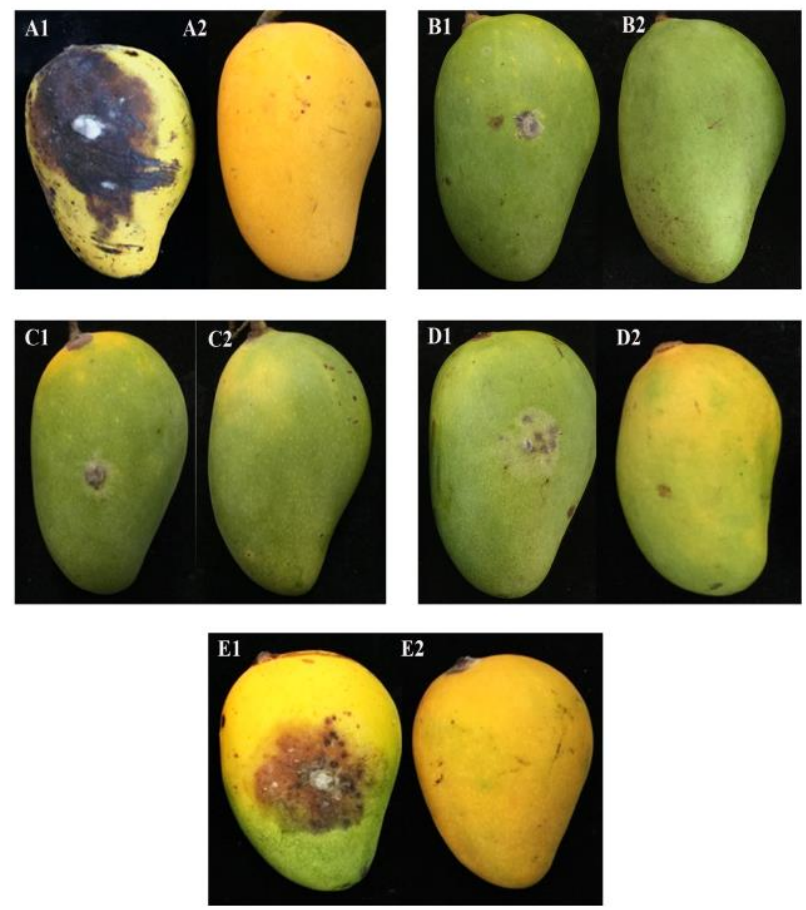

Fig. 4 - Mango fruit 7 days after being soaked in garlic cloves extract for 1 hour. A Inoculated A1 and non-inoculated A2 control mango soaked in sterile distilled. B Inoculated B1 and noninoculated B2 mango soaked in 100\% extract. C Inoculated C1 and non-inoculated C2 mango soaked in $75 \%$ extract. D Inoculated D1 and non-inoculated D2 mango soaked in 50\% extract. E Inoculated E1 and non-inoculated E2 mango soaked in $25 \%$ extract. 


\section{Acknowledgements}

This work was partially funded by the Research Grant Universiti Putra Malaysia.

\section{References}

Akem CN. 2006 - Mango anthracnose disease: present status and future research priorities. Journal of Plant Pathology 5(3), 266-273.

Alli JA, Boboye BE, Okonko IO, Kolade AF, Nwanze JC. 2011 - In-vitro assessments of the effects of garlic (Allium sativum) extract on clinical isolates of Pseudomonas aeruginosa and Staphylococcus aureus. Advances in Applied Science Research 2(4), 25-36.

Arauz LF. 2000 - Mango anthracnose: economic impact and current options for integrated management. Plant Disease 84, 600-611.

Arora S, Kaur J. 2007 - Antibacterial activity of some Indian medicinal plants. Journal of Natural Medicines 61, 313-317.

Curtis H, Noll U, Stormann J, Slusarenko J. 2004 - Broad-spectrum activity of the volatile phytoanticipin allicin in extracts of garlic (Allium sativum L.) against plant pathogenic bacteria, fungi and Oomycetes. Physiological and Molecular Plant Pathology 65(2), 79-89.

Daniel CK, Lennox CL, Vries FA. 2015 - In-vitro effects of garlic extracts on pathogenic fungi Botrytis cinerea, Penicillium expansum and Neofabraea alba. South African Journal of Science 111, 1-8.

FAO. 2010 - FAOSTAT. Food and Agriculture Organization of the United Nations. http://faostat.fao.org/default.aspx.

Harris JC, Cottrell S, Lloyd D. 2001 - Antimicrobial properties of Allium sativum (garlic). Applied Microbiology and Biotechnology 57, 282-286.

Johnson GI, Cooke AW, Mead AJ, Wells IA. 1991. - Stem-end rot of mangoes in Australia: causes and control. Acta Horticulture 291, 288-295.

Josling P. 2001 - Preventing the common cold with a garlic supplement: a double-blind, placebo controlled survey. Advance Theraphy 18, 4 .

Kouame KG, Abo K, Dick E, Bomisso EL et al. 2010 - Artificial wounds implication for the development of mango (Mangifera indica L. Anacardiaceae) fruit disease caused by Colletotrichum gloeosporioides (Penz.) Sacc. (Glomerellaceae). International Journal Biology Chemistry Science 4(5), 1621-1628.

Mendonca-Filho RR. 2006 - Bioactive Phytocompounds: New Approaches in the Phytosciences. In: Modern Phytomedicine. Germany: Wiley-VCH Verlag GmbH \& Co. Weinheim.

Mondali N, Mojumdar A, Chatterje S, Banerjee A et al. 2009 - Antifungal activities and chemical characterization of neem leaf extracts on the growth of some selected fungal species in vitro culture medium. Journal Application Science Environment Management 13(1), 49-53.

Munirah MS. 2017 - Characterization, pathogenicity and host range analyses of Lasiodiplodia and related species isolated from fruit rot of mango. Master thesis, Universiti Putra Malaysia.

Narayana CK, Pal RK, Roy SK. 1996 - Effect of pre-storage treatments and temperature regimes on shelf-life and respiratory behaviour of ripe Baneshan mango. Journal Food Science Technology 33, 79-82.

Nene YL, Thapliyal PN. 1993 - Fungicides in Plant Disease Control, 3rd ed. New Delhi, India, Oxford and IBH Publishing Company, 531-532.

Ni H, Yang H, Chen R, Liou R, Hung T. 2012 - New Botryosphaeriaceae fruit rot of mango in Taiwan: identification and pathogenicity. Botanical Studies 53, 467-478.

Okigbo RN, Osuinde MI. 2003 - Fungal leaf spot diseases of mango (Mangifera indica L.) in Southeastern Nigeria and biological control with Bacillus subtilis. Plant Protection Science 39, 70-77.

Park SI, Stan SD, Daescheler MA, Zhao Y. 2005 - Antifungal coatings on fresh strawberries (Fragaria $x$ ananassa) to control mold growth during cold storage. Journal Food Science 70, 202-207. 
Patel V, Patel R. 2016 - The active constituents of herbs and their plant chemistry, extraction and identification methods. Journal of Chemical and Pharmaceutical Research 8(4), 1423-1443.

Perelló A, Noll U, Slusarenko AJ. 2013 - In vitro efficacy of garlic extract to control fungal pathogens of wheat. Journal of Medicinal Plants Research 7(24), 1809-1817.

Sekhar C, Selvarajan M, Pounraj A, Praghadeeswaran M. 2013 - Production and export of mango in India: a paradigm to the developing nations. American International Journal of Research in Humanities, Arts and Social Sciences 13(337), 78-84.

Senhaji B, Ben Hmamou D, Salghi R. 2013 - Asteriscus imbricatus extract: antifungal activity and anticorrosion inhibition. International Journal of Electrochemical Science 8, 6033-6046.

Shinde RP, Barhate BG, Musmade NA. 2016 - In vivo efficacy of garlic extract and yeast for the control of post-harvest diseases of mango and papaya. International Journal of Plant Protection 9(2), 632-634.

Slusarenko A, Patel A, Portz D. 2008 - Control of plant diseases by natural products: allicin from garlic as a case study. European Plant Pathology 121, 313-322.

Vasile BR, Vlaicu B, Butnariu M. 2012 - Chemical composition and in vitro antifungal activity screening of the Allium ursinum L. (Liliaceae). International Journal Molecular Science 13, 1426-1436.

Yenjit P, Intanoo W, Chamswarng C, Siripanich J, Intana W. 2004 - Use of promising bacterial strains for controlling anthracnose on leaf and fruit of mango caused by Colletotrichum gloeosporioides. Walailak Journal of Science \& Technology 1(2), 56-69. 